\title{
Toribio Esquivel Obregón: del hombre público al privado: "Memorias" a la sombra de la revolución*
}

Guillermo Zermeño Padilla

ULA

\begin{abstract}
Análisis de la idea de revolución en las Memorias, es decir en el recuerdo, de Esquivel Obregón.
\end{abstract}

I

A 1 preparar la edición y publicación de las Memorias del político y abogado guanajuatense Toribio Esquivel Obregón, fui descubriendo a un hombre público que recuerda, para rescatar del olvido, costumbres y hábitos del pasado mexicano; aspectos que sin descuidar la vida pública quedan enmarcados sobre todo por la

- Este ensayo constituye el estudio introductorio de las Memorias de Toribio Esquivel Obregon, que serán publicadas por la Universidad Iberoamericana, el Consejo de Cultura de León y el Patronato Toribio Esquivel Obregón.

${ }^{1}$ Esquivel Obregón, Memorias, s.f. vida privada: la personal, la familiar y social.

El documento, como seguramente otros muchos que circulan por ahí todavía, me pareció que ofrece-posibilitado por el clima político de esta última década del siglo-, elementos suficientes para abrirse a una comprensión más amplia de lo que pudo haber significado para la sociedad mexicana el paso del siglo XIX al $\mathrm{xx}$, lo que hasta ahora en la historiografia ha quedado delimitado casi con exclusividad por el evento denominado como revolución mexicana. Pero, curiosamente encontré, al mismo tiempo, que es la revolución la que funciona también como catalizador principal de esa obra de rescate, como una especie de filtro negativo 
de una fotografia que no deja ver con nitidez las imágenes ahí expuestas.

Aunque el contenido de las Memorias no habla propiamente de la revolución mexicana, ya que se limita a recoger hechos y dichos de un periodo anterior -1864-1888-, y se concentra en una ciudad como León (Guanajuato), bastante marginal con respecto al proceso revolucionario, sin embargo entre líneas y a veces en forma más explícita, la revolución aparece como el implícito necesario que articula y dota de sentido al escrito, como referente negativo, como se dijo. Por eso hablamos de la revolución como de una "sombra". Pero también será interesante ver de qué revolución se está tratando.

La exploración de la relación entre memoria y revolución, me llevó a plantear la siguiente proposición acerca de los motivos de Esquivel Obregón para "memoriar" en los siguientes términos: "Recuerdo antes de que la revolución termine por hacer olvidar todo lo pasado", la cual me pareció que podría ser sugerente para observar el funcionamiento del término "revolución" ligado por un lado a la forma de recordar y por el otro, probablemente, como una forma embrionaria de lo que sería propiamente la historiografia de la revolución mexicana, vista en su sentido amplio como la surgida al cuidado y cobijo del régimen político y económico de la revolución. La primera cuestión a dilucidar entonces se desdobla de la siguiente manera: establecer la génesis de la escritura de las Memorias implica esclarecer el significado del término "revolución".

\section{II}

A través de sus Memorias se observa que Esquivel Obregón recuerda para preservar la memoria del olvido, ayudado de la escritura. Lo hace porque advierte al mo- mento de escribir-recordar (1906-07) que ese presente ya no es como el anterior. La escritura le permite establecer marcas que señalan diferencias entre una época y otra, entre un presente y un pasado. Su manuscrito deja ver a un hombre que posee una conciencia clara acerca del hecho de que las cosas en el país estaban cambiando o habían cambiado en forma irreversible: en el modo de hacer política, en la arquitectura, en los hábitos de aprendizaje y de comportamiento, en las formas de conversar y de acceder a los libros, etc. Lo evidente era: el mundo moral o de las costumbres había entrado en un proceso acelerado de transformación. Cuando está escribiendo constata con frecuencia que muchos gustos, muchas prácticas sociales eran diferentes de cuando fue niño y joven, o tendían a desaparecer.

En Toribio Esquivel Obregón esta conciencia no está exenta de dramatismo: toda ruptura con el pasado o en la tradición conlleva la alegría de lo nuevo, pero a la vez, la tristeza propia de cuando algo (alguien) se muere. ${ }^{2}$ Sin embargo, la herida más profunda provenia del hecho de que las novedades que se arremolinaban en su presente iban dejando tras de sí un tiempo largo, englobado bajo el signo epocal de la colonia.

Resumiendo: el testimonioen primera persona de Esquivel Obregón, está sellado por la conciencia de que la mayor parte de las prácticas sociales que se conocen hasta ese momento y que remiten a la colonia, están llegando a su fin o están siendo modificadas.

Llegados a este punto resulta necesario intentar fijar los momentos que podrían señalar los ejes temporales de la elaboración de las Memorias desde los cuales Esquivel Obregón lanza su mirada

\footnotetext{
${ }^{2}$ Ibid., t. II, p. 224.
} 
hacia el pasado. Así, es posible descubrir dos periodos en los que el autor detecta, establece, compara, anota los cambios habidos, uno antes de la revolución armada y otro después de la misma.

En efecto, se cuenta en el Fondo Toribio Esquivel Obregón ${ }^{3}$ con un par de libretas manuscritas de notas y apuntes cuyas fechas van del 12 de enero de 1906 en Morelia, hasta el mes de abril de 1907 en León (Guanajuato). Se puede observar que su autor se propuso como tarea, avanzar en la recuperación de la historia reciente o contemporánea de León (su contemporánea) con una cuota de escritura mensual; excepto la inicial, fechada en Morelia, todas las demás serán de León (de mayo, junio, julio, septiembre, octubre, noviembre, diciembre de 1906 , y la de enero-marzo, y la última, de abril de 1907). En esta libreta EsquivelObregón se detiene en las páginas 121 y 122 , y establece la primera gran revolución causada por la introducción del ferrocarril, y motivo último de sus apuntes. Ahí se puede leer:

He procurado dar una idea de lo que era León por los años de 1870 a 1880 antes de que se borren las huellas de la antigua población, porque va a ocurrir una transformación completa al contacto con el ferrocarril. Antes de esa época, el aislamiento casi completo hizo que se conservaran intactas las costumbres y los edificios y las cosas de la época colonial; apenas si la reforma, que obró una transformación tan completa en el dominio político y económico, trajo algún cambio en León, pues casualmente aquí había pocas propiedades de manos muertas y el distrito entero continuó su antigua marcha.

Por una rara coincidencia la ciudad y

${ }^{3}$ Caja libretas, Fondo Toribio Esquivel Obregón, Acervos Históricos, Universidad Iberoamericana (en adelante F. TEO/UIA). yo salimos a la vez de nuestra infancia. Comienza pues la juventud, sólo que León gozará de ella por muchos años después que yo haya pasado la última etapa de la vida. Partimos en el mismo tren; yo para bajarme en la estación más próxima; la ciudad seguirá su larga carrera sin acordarse de los que con ella comenzaron el viaje.

Esquivel Obregón retomará esta libreta unos 20 años después, entre 1929 y 1933, pasada la revolución armada, y realizará una retranscripción del texto. De ésta surgirá la versión final del manuscrito correspondiente al volumen II de las Memorias. No se trata en lo fundamental, como se verá después, de un registro totalmente nuevo, sino la confirmación de algunas tendencias apuntadas entonces, o la ampliación y ejemplificación de las mismas, o la añadidura de nuevas reflexiones orientadas por los acontecimientos después de 1907, que le darán una mayor profundidad a su idea de revolución.

Por ejemplo, en relación con la cita anterior, nos dice en cuanto a las "propiedades muertas" que éstas "se reducían a las casas del hospital de San Juan de Dios y a las propias del Ayuntamiento, pues los bienes cuantiosos que allí habian tenido los jesuitas desde la época virreinal habian entrado a ser de la propiedad particular tiempo hacía". O confirmaba la idea del inicio de una nueva época: "Puede decirse que una nueva era se iniciaba con la llegada del ferrocarril..."

El periodo que va entre 1906-7 y 192933 no es continuo. La memoria se corta por enmedio, debido primero a una participación política desafortunada (190913) y, segundo, a la salida forzada del país a Estados Unidos (1913-24). Esta

\footnotetext{
'Esquivel Obregón, Memorias, S.F., t. II, p. 170.
} 
discontinuidad me condujo a la siguiente consideración acerca de la idea de revolución como posible parteaguas $-\sin$ negar las continuidades- de un México colonial, incluyendo el periodo nacional, de otro no colonial, desconocido hasta entonces; pero, de una revolución plagada de connotaciones no unívocas.

Es cierto que la idea genérica de revolución se vincula inmediatamente a la noción de un giro total de 180 grados. Pero históricamente, por lo que parece, esta idea no se manifiesta de una sola vez en su totalidad. Existen múltiples pequeñas "revoluciones" cuya resultante no es la suma de todas, sino sólo las partes de un proceso lento de deslavamiento de las viejas formas, propiciado por múltiples y variadas acciones de los hombres en sociedad. Intentaré explicarme.

La generación de Esquivel Obregón, la de los nacidos durante la guerra de Reforma, piensan en la revolución como circunscrita en lo fundamental a cambios de índole política, cambios en la conducción de mando casi siempre a través de una "asonada", de una revuelta $o$, simplemente, de un golpe de Estado. Puede haber cambio político, pero no necesariamente se sigue de ahí el paso de una sociedad a otra. No conocen más que esa sociedad heredada de la colonia, a la que si bien intentan transformar por medio de la introducción de nuevas fórmulas educativas o económicas, e incluso políticas, aquélla permanece más o menos la misma. Por eso, la vía pacífica al cambio de poderes mediante la mecánica de la democracia electoral será vista hacia finales de la primera década de este siglo, como la novedad o alternativa a las formas clásicas o conocidas hasta entonces. Madero y su grupo antirreeleccionista, respaldado por la ley pronunciada en 1857 , será sin embargo presa y víctima de fuerzas sociales que no conocen sino la práctica social de la asonada. Pero, esta vez, la revolución que va a conocer y va a tomar por sorpresa a Esquivel Obregón y a otros de los protagonistas, llevará otros ingredientes, no meramente políticos. Contendrá los elementos de una revuelta social más o menos generalizada, según las condiciones de cada una de las regiones del país. Uno de los filos de la navaja de la revolución lo percibirá don Toribio antes de 1910. Pero el otro filo, lo acabará de comprender hasta bien pasada la "decena trágica", después de haber rumiado los alcances de la contienda armada durante y después del exilio.

Antes de los sucesos que se van a desencadenar a partir de 1910, Esquivel Obregón conoce a la revolución como revuelta política. De alguna manera, si participa primero con Madero y después con Huerta, lo está haciendo desde esta óptica. Desconoce que la revolución será más que eso. Esto lo sabrá pasados los acontecimientos: cuando la transformación no sólo política -cambio de los puestos de mando- sino social, se vea como irreversible. Esto dicho en términos genéricos, porque lo que está viendo en realidad Esquivel Obregón es algo mucho más profundo y que no es patrimonio exclusivo de la revolución de 1910: la "revolución de las costumbres". Es en este ámbito en donde el régimen del porfiriato, después de 1880 , y el de la revolución se entrelazan poderosamente. Son parte de un proceso más largo que los atrąviesa e incluso se continúa hasta hoy en día.

En efecto, Esquivel Obregón ya sabe, como el geógrafo e historiador Antonio García Cubas, que antes de 1910 está teniendo lugar una revolución del mundo moral. El origen de esta transformación en sentido estricto no radica en el mundo de la política formal, sino de la 


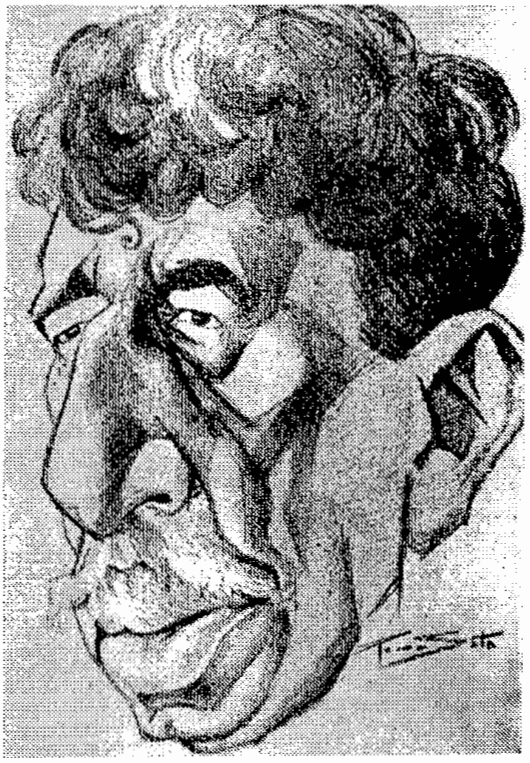

vida privada impactada por la ciencia y la técnica (del saber y del poder de transformación material de las cosas), que se expresa en la creación de nuevos hábitos de pensamiento a través de nuevas lecturas o de nuevas formas de vida mediante el uso de nuevos medios instrumentales. Ningún otro evento sintetiza el impacto de esta "revolución" como la aparición del ferrocarril, y lo que éste implicó. Esta es la revolución que hermana a dos épocas supuestamente vistas como antagonistas.

La otra revolución que detecta a su regreso del exilio durante la década de los veinte es la que hemos conocido todos los nacidos durante el siglo Xx: el paso del régimen político porfirista, al "revolucionario". Y aquí convendría preguntarse ¿cuál de las revoluciones podría considerarse como más genuina en cuanto a su alcance? La respuesta, examinado el caso de Esquivel Obregón, se dirigiría con toda seguridad en el sentido de la revolución de las costumbres, esto considerando que la forma de hacer política es también inherente a las costumbres, y que el tejido social está hecho de prácticas detectables por el historiador. Pero también es cierto, con Marx, que la violencia revolucionaria fue como la locomotora que aceleró el progreso y la transformación de las costumbres de la sociedad incubadas en el régimen anterior. Es por eso que Esquivel Obregón habiendo reñido con una de las revoluciones, la político-militar, aceptará ser hijo de su tiempo, es decir de su sociedadtradición-costumbre; observará su transformación y se dará a la tarea de su conservación por medio de la escritura, antes de que los nuevos vientos-ciencia, técnica y política-, acaben por barrerla.

Como se apuntaba arriba, evidentemente la revolución no puede ser vista como la suma de las partes señaladas. Tampoco es fácil emprender la tarea de establecer las relaciones causales entre sus componentes. Ni es el propósito de este ensayo. Lo que se busca más bien es abrir la idea de revolución como el fin de una época o sociedad y el paso de otra. Revolución que pone fin a la época colonial en el ámbito de las costumbres privadas y no necesariamente en el de las públicas, visto como un proceso complejo, multicausal, preñado de violencia, en la que la parte armada, no por ser la más dramática, es la más definitiva en cuanto a la hondura de la transformación en las relaciones sociales entre los hombres. Y aquí me dejo guiar por la idea expresada por el historiador inglés Peter Brown, ${ }^{5} \mathrm{en}$ el sentido de que es en las "cosas peque-

\footnotetext{
s Brown, Antigüedad, 1989.
}

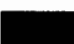


ñas" en las que se puede distinguir con mayor claridad qué tanto va cambiando o ha cambiado una sociedad; esto, finalmente, porque significa que los cambios han pasado a ser parte de un "inconsciente colectivo". Me parece que es en este ámbito en el que se inscribe uno de los intereses principales de la recuperación de este tipo de Memorias como las de Esquivel Obregón.

Establecido lo anterior, creo que el tema central de este trabajo es ver cómo opera esta idea de revolución en la forma de recordar de Esquivel Obregón, lo cual le permitirá crear una mayor profundidaden cuanto a la idea del pasado-pasado o muerto, que de manera gradual va dejando de afectar al presente o contemporaneidad establecida por lo que se conoce como la revolución mexicana.

Hasta aquí se ha intentado fijar los puntos temporales del levantamiento de las Memorias, sus líneas generales y sus motivos. He querido dejar asentado que el prisma de la revolución es el cristal, como proceso más largo y como trauma en el tiempo corto, a través del cual serán recogidos los recuerdos. Lo primero como efecto de los cambios técnicos y científicos, y lo segundo, como efecto de su participación política que sellará su relación ambivalente con la idea de cambio: por un lado como reconocimiento de ser parte del mismo; por el otro, como distanciamiento reservado. Dualidad que tal vez podría explicar el por qué Esquivel Obregón, o personas como él, de "temple liberal", y más tarde conservadores declarados, se comportaron como lo hicieron, frente a la "revolución".

En adelante quedaría por puntualizar un poco más en EsquivelObregón su paso por la política o mundo público, al mundo de los privados, lugar propio donde se realiza el ejercicio de la memoria.
El HOMBRE PÚBlICO: SU PASO POR LA REVOLUCIÓN

III

Cuando Toribio Esquivel Obregón, ex ministro de Hacienda del gabinete de Victoriano Huerta, regresa a México del exilio neoyorquino en 1924, tiene 60 años de edad. Se dispone entonces a reiniciar sus actividades profesionales como jurisconsulto en la ciudad de México. Distante de la política activa, sin embargo mantendrá conexiones con importantes miembros de lo que será a partir de 1939 el Partido de Acción Nacional. Incluso en 1946, poco antes de morir, será candidato a senador por el Partido Fuerza Popular, fundado poco antes por el sector político del movimiento social sinarquista. Lo importante a señalar es que al reintegrarse a la vida nacional se mantendrá siempre del lado de la oposición silenciosa al régimen revolucionario instaurado.

En este contexto, de entre las sombras del hombre público, y de la mano de la escritura, irá resurgiendo el "hombre privado" que fue en su infancia y en su juventud, así como el ciudadano-periodista que en forma un tanto casual se convirtió de pronto en un hombre público.

En efecto, los siguientes diez años, 1924-34, testigos de la entronización del poder sonorense en la política nacional, servirán a nuestro autor para poner un poco de orden en los recuerdos de las décadas previas a los años azarosos de la revolución. Se trata de un pasado que cubre casi 50 años de hechos y recuerdos vinculados a la vida privada. Sin embargo, atravesados también por la vida pública. Los límites entre una y otra esfera serán apenas perceptibles en sus escritos. Pero también es cierto que en los 
años en que hará memoria, un cierto pudor se introducirá, al deslindar un escrito como las Memorias que no publicará porque su destinatario es la esfera íntima familiar, y otro escrito que sí aparecerá bajo el sello editorial Botas, dirigido a responder a sus detractores políticos y establecer el marco de su defensa por su participación en el gabinete huertista después de haber sido antirreeleccionista.

El estigma de haber participado con el huertismo frente a una revolución que resultó ser más que una simple revuelta estilo siglo XIX y que congregó a su alrededor como ningún otro movimiento campesino viejos agravios, se convertirá para Esquivel Obregón, y seguramente para otros, en una marca que requerirá ser exhumada a través de la escritura. Es en estos años, pasada la contienda civil, restablecido el régimen constitucional, en los que Carranza (n. 1859) y los más jóvenes, Obregón (n. 1880) y Calles (n. 1877), sacarán la mejor parte, incluso a costa de Madero (n. 1873), cuando Esquivel Obregón se dará a la tarea de hurgar entre sus papeles viejos, para despertar a la memoria del olvido.

\section{IV}

La vida pública de Esquivel Obregón fue corta. Apenas si duró escasos cinco años. Se inicia en 1909 cuando se integra al Partido Antirreleccionista de Francisco I. Madero y Francisco Vázquez Gómez, y concluye en 1913 después de renunciar al gabinete huertista. Menos de un quinquenio de aparición en público bastará para imprimirle a su vida posterior un sello dramático. El asesinato del presidente Madero y su vinculación con la administración de Victoriano Huerta, serán una sombra en la vida de Esquivel Obregón que requerirá ser exorcizada.

En 1934, 20 años después de la decena trágica, publicará su libro Mi labor en servicio de México. En su dedicatoria a su esposa Laura, se revela su decepción y desconcierto ante su paso por la política. El hombre privado, en voz de su mujer -quien pudo ver mejor la "inanidad" de la política y que apenas si supo de ella-, le dice al hombre público, que las "satisfacciones" de la política fueron más bien pocas y efimeras.

En el caso de Esquivel Obregón, el curso inesperado de los acontecimientos revolucionarios convirtió los presagios y la voluntad por contribuir a la solución de los problemas agrarios y hacendarios de México, en un padecimiento cuyo pathos será llevado y rumiado en la intimidad.

La entrada de Esquivel Obregón en la política nacional fue un tanto fortuita. De abogado, profesor y director de la Escuela de Instrucción Secundaria de León, incursiona en el periodismo, haciendo crítica de algunos aspectos de la política hacendaria del ministro Limantour. Esto será suficiente para llamar la atención de Madero y el pequeño grupo del P'artido Antirreeleccionista en gestación. Incluso, será invitado a ocupar la candidatura a la vicepresidencia al lado de Madero. Esquivel Obregón acepta sin estar totalmente convencido de la propuesta maderista. Entra en la vida pública, al parecer, titubeante. En este momento piensa en un desarrollo pacífico de los acontecimientos; calcula que la deposición democrática del gobierno de Díaz bastará para acceder al cambio político visto como necesario. No sospecha que la violencia imumpirá con fuerza y que barrerá toda posibilidad de evolución pacífica. De ahí que conforme vayan apareciendo signos contrarios a sus expectativas, va a ir en aumento su reserva con respecto al maderismo y, en consecuencia, a la revolución. Pero el mismo 
Madero desconocía el tamaño de la fiera que acabaría incluso por devorarlo a él mismo y a muchos de sus hijos. Esquivel Obregón, entonces, se verá víctima de acontecimientos que nunca quiso asociar a la transformación pacífica del régimen porfirista.

A la distancia, Esquivel Obregón intenta explicar en su libro el curso de los hechos. Ahí señala que muchos de los que participaron entonces formaban parte de una generación sin experiencia política previa, en extremo optimista e ingenua, que no hicieron sino concentrar el cúmulo de problemas que venía cargando el país desde la colonia, en el ejercicio personalista del poder de un solo hombre. Su error fue no haberse percatado de qué tanto había cambiado el país para 1910 , debido a la otra revolución no tan silenciosa que humeaba ya a través de campos y ciudades del país.

Pero también es importante considerar, en el casu de Esquivel Obregón, la edad que tiene al iniciarse en la vida pública. Un hombre de 45 años de edad ya no es tan joven como para plantear la vision de un México distinto del conocido hasta entonces, si antes no la ha cultivado. Sus pies y hábitos de pensamiento son los de un hombre crecido a la sombra de los gestos pacificadores de don Porfirio; pero también son los de alguien que es consciente de los problemas que aquejan al país y que han quedado sin solución por generaciones. En unos apuntes manuscritos de un libro en preparación fechado en León el 4 de agosto de 1910, frente a la proximidad de las fiestas del centenario de la independencia, apunta lo siguiente:

El paseo del pendón en 1910 cubrirá de rubor al pueblo mexicano por la triste ironía de su destino, porque a través de cuatro siglos no ha conseguido indepen- dizarse del tirano, que es el régimen español; sólo ha logrado encontrar en la palabra eufónica que lo adorne con el nombre de política de unificación. Debido a ella, México es ahora, como lo era en la época colonial, el país de la desigualdad. He allí el progreso. ${ }^{6}$

Esquivel Obregón, como el mismo Madero, pertenece a una generación que todavía piensa que al resolverse el problema político, el de la libertad de los municipios, el de la elección de los gobernantes, los demás problemas irán cayendo por su propio peso. Aquí es importante ver a este conjunto de líderes regionales que irán emergiendo durante la revolución como parte de una elite que se siente con derechos propios para gobernar.

Una cierta miopía, propia del desconocimiento del futuro, hará que la puerta abierta en forma titubeante por Esquivel Obregón, al acceder al mundo público, se cierre en forma un tanto intempestiva. Para unos antes, para otros después, como Soto y Gama, Luis Cabrera y Vasconcelos, sucederá algo similar, en la medida en que vayan siendo desbordados por la fuerza de los acontecimientos. En ese sentido la revolución y su futuro, salvo excepciones, será más bien de los hombres nacidos a la sombra del vértigo producido por el rugir y la solemnidad del ferrocarril y las invenciones técnicas, locomotivas y de comunicación, que le seguirán.

En esos años, pues, cuando el capital norteamericano comienza a regresar y a invadir de nuevo al país, y los negocios parecen retomar el rumbo anterior a 1910 , Esquivel Obregón hace memoria y recuerda cómo fue que se incorporó al maderismo, y cómo, aunque aceptó la cartera huertista, no tuvo que ver con el

\footnotetext{
${ }^{6} \mathrm{~F} . \mathrm{TEO} / \mathrm{UIA}$, archivo muerto, caja 1.
} 


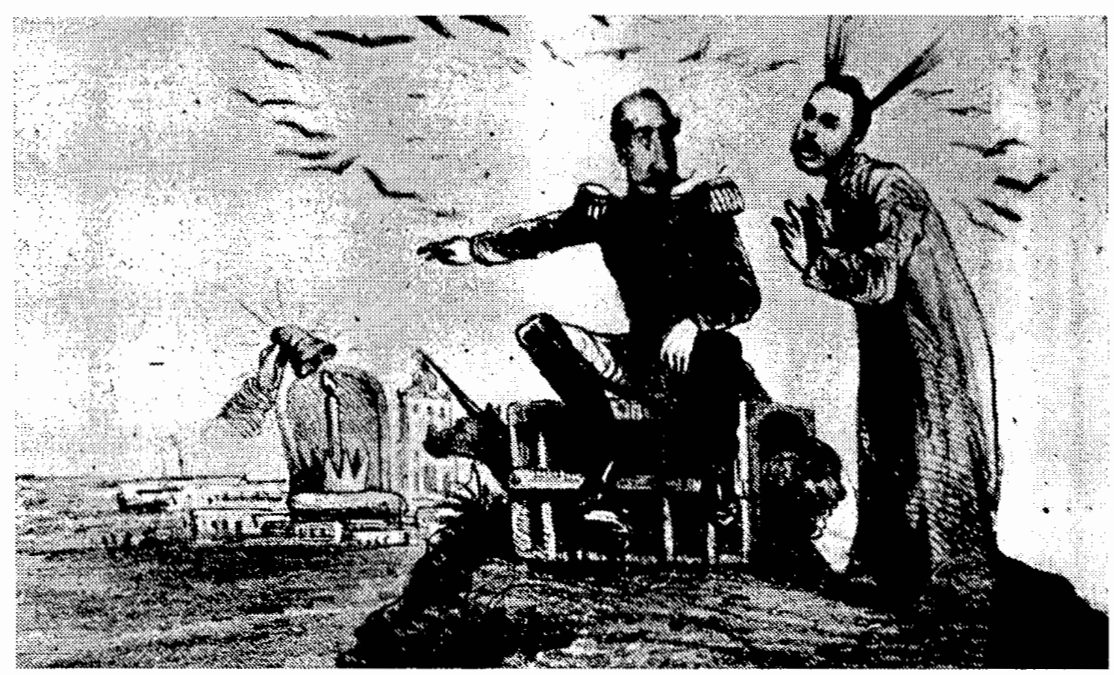

asesinato de Madero. De cara ante la opinión pública, pero sobre todo ante sí mismo, mediante el ejercicio de la memoria, busca la reconciliación consigo mismo, consciente de que los tiempos pasados ya no volverán a ser como antes. El regreso del exilio durante la década de los años veinte, significará el reencuentro con un México que ya no es el que abandonó en 1913, pero cuyas sombras y fantasmas seguirán reapareciendo una y otra vez, en el campo de fuerzas de la memoria. Aun cuando sus referentes pudieran ser enteramente públicos, la memoria y su funcionamiento tenderá a ser enteramente privada.

EL HOMBRE PRIVADO: LAS MEMORIAS COMO RECORDATORIOS

\section{V}

Tras haber consignadoestos hechos que no significan nada por sí mismos y que, sin embargo, y para cada uno de noso- tros, llevan más lejos que nuestra propia historia e incluso que la historia a secas, me detengo, presa de vértigo ante el inextricable enmarañamiento de incidentes y circunstancias que, más o menos, nos determinan a todos.

Marguerite Yourcenar ${ }^{7}$

Las Memorias de Toribio Esquivel Obregón fueron recogidas, como ya se mencionó, entre los años 1930 y 1933 , si nos remitimos al fechado del original mecanografiado, en el que el tomo I, de 129 páginas, lleva la fecha de diciembre de 1930 y el II, más largo, de 268 páginas, de enero de 1933, fecha que señala su terminación. Existe también el manuscrito original de las mismas, que fue elaborado, como se vio, con base en materiales recogidos con anterioridad a 1910.

Enlas Memorias, Esquivel Obregón no transmite la sensación de estar entregando certezas, ni tampoco intenta hacer la defensa política de sí mismo como las

${ }^{7}$ Yourcenar, Laberinto, 1984, p. 15. 
Memoriaspolíticas de Francisco Vázquez Gómez, tampoco transmite la coherencia de un paso triunfal por la historia nacional-revolucionaria como las $\mathrm{Me}$ morias de Gonzalo N. Santos. ${ }^{8}$ A lo mucho intenta recoger una cierta tradición política liberal, conjuntada con una preocupación aristocratizante, vinculada sobre todo a la familia de los Obregón. Pero la forma un tanto inconexa de su recuperación hace pensar más bien en unas Memorias que son en realidad, siguiendo a Marguerite Yourcenar, unos Recordatorios, es decir, retazos de recuerdos, seguramente no todos de primera mano, informaciones provenientes de fragmentos de cartas, libretas de apuntes, amarillentos papeles notariales, compendios de genealogía, todos a la vez reales e irreales, los que, sin embargo, constituyen el medio necesario que nos puede vincular al Toribio Esquivel Obregón de 1932 con aquél de su niñez, infancia y juventud de 1864 a 1888 , recuerdos enmarcados por escenarios de la ciudad de León y México. Son frag. mentos de hechos entresacados de archivos personales y de tradiciones orales, los que ensamblados podrán producir la imagen de un personaje, de un medio social o de un entorno. Memoriasque son una simple y "momentánea escapada sobre lo que ya no tiene nombre ni forma".?

Su escritura, realizada con una caligrafia Palmer impecable, clara y simétrica, nos muestra ciertamente no a un escritor preocupado por el estilo literario-sólo a veces observable-; su letra y composición dejan ver más bien a un jurista y a un memorialista, que conjuntan la ausencia de tachones o equivocaciones al redac-

8 Vázquez Gómez, Memorias, 1980; Santos, Memorias, 1986.

${ }^{9}$ Yourcenar, Laberinto, 1984, p. 16. tar, con un cierto desorden al momento de tejer el abanico de recuerdos. La memoria, ayudada de la escritura, fluye encuadrada por un orden que no deja salirse de la raya. Las irregularidades sólo se advertirán en la manera de asociar los recuerdos, nunca totalmente concordantes entre sí. Y es que tampoco fueron pensadas como las Memorias de un hombre público, ejercicio necesario de autojustificación o explicación de los actos realizados. Tampoco se trata del orden del historiador que por necesidad imprime a su forma de recordar un encuadre lógico-narrativo a fin de poder ser persuasivo ante sus propios colegas, situados en la misma frecuencia. La etapa de los nuevos historiadores de oficio apenas estaba naciendo cuando Esquivel Obregón estaba muriendo en 1946.

En su tiempo hay pocas opciones profesionales: medicina, ingeniería o derecho, tal vez comercio. Todas presuponen más o menos una filosofía de la historia que las sustenta: el positivismo, entendiendo a éste como dice Peter Gay, menos como una escuela organizada, y más como "una actitud profunda con respecto al hombre, la naturaleza y los estilos de investigación": se trata de llevar el programa y los métodos de las ciencias naturales, debido a sus éxitos, al campo de la investigación de las acciones y pensamientos del mundo humano, privado y público. ${ }^{10}$ Desde este horizonte se establecerá la interacción de los procesos cognoscitivos, jurídicos, políticos y económicos, con la historia y la naturaleza. Así, en México, habrá médicos-historiadores como Nicolás de León, e ingenieros-historiadores como Antonio García Cubas, y juristas-historiadores como Toribio Esquivel Obregón.

${ }^{10}$ Gay, Freud, 1989, p. 58. 
Tenemos entonces en Esquivel Obregón a un hombre de leyes, obsesionado por el orden y la disciplina; pero también a un hombre que acude a su "memoria", en su caótica conformación, para rescatarse a sí mismo en lo privado.

\section{$\mathrm{VI}$}

Las Memorias fueron escritas, aunque no en forma exclusiva, para ser leîdas por los integrantes de su familia. Las mira como a una forma de preservar del olvido una cierta estirpe familiar. Pero también es consciente de que pueden interesar a un círculo más amplio y extrafamiliar. Sabe del peso y de la importancia que tiene la tradición para la conformación de la identidad cultural de un grupo o de un pueblo. Sabe que los aspectos "privados" u ocultos de la vida, ese mundo de detalles de los que está hecha la vida cotidiana, en apariencia insignificantes, proporcionan claves valiosas del ser cultural de un grupo o de una sociedad.

Casi toda la primera parte del texto se ocupa de la genealogía familiar, de asuntos que tal vez interese conservar sólo a los miembros de la familia.

Pero aunque las Memorias están fuertemente atadas a su biografía personal, ésta se va entrelazando con aspectos públicos de la sociedad y de la ciudad en la que creció. Así, la ciudad de León se convertirá también en protagonista del escrito, al lado de personajes de la vida política, cultural y social del entorno vital, personal y familiar.

Circunscritos por su historia y por las redes de lealtades y convicciones, personales y sociales, sus escritos son expresión de un interés por la salvaguarda de la tradición. Ésta es, para Esquivel Obregón, el fundamento explicativo de una cultura o identidad social específica, la cual, en términos sociológicos, se va a manifestar sobre todo en los comportamientos cotidianos, en las formas de vestir y de pasear, de comer y de charlar. Por ello sabe, al estarlas elaborando, que su obra de rescate pensada sobre todo para su círculo familiar puede caer no obstante, en "manos de personas extrañas", pero que si fueran "inteligentes o simplemente curiosas de conocer los diversos aspectos de la vida mexicana, la historia de las familias mexicanas", debería serles "interesante y sugestiva", ya que, añade, "la nación mexicana se compone de esas familias, y si pudiéramos conocer mejor la historia de éstas comprenderíamos mejor la de aquélla y la depuraríamos de muchos errores". ${ }^{11}$ Así, cruzado el umbral de lo privado, visto éste sólo como un velo, entonces la vida pública podría comenzar a adquirir nuevos relieves.

En su declaración de motivos -englobados por el recate de la tradición-, si se contemplan aquellas décadas en que el escritoes redactado, se puede destacar cierta oposición a una dinámica del olvido instaurada por la idea de que todo futuro será siempre mejor que todo pasado. La tradición, identificada en buena medida con el pasado colonial, pasará así paulatinamente a ocupar un lugar en el campo de las resistencias a cambios impulsados por una "revolución modernizante". Desde esta perspectiva la revolución será vista como la principal amenaza para la conservación de una identidad cultural "mexicanista" bañada por las tradiciones de la vieja España. ${ }^{12}$ Para estos años, luego del decenio empleado en Estados Unidos, Esquivel Obregón ha dejadoatrás su liberalismo-porfirista, identificará a

${ }^{11}$ Esquivel Obregón, Memorias, s.f., t. 1, p. 7.

${ }^{12}$ A su vez, la revolución seleccionará al indigenismo (como fundamento del ser original de la "mexicanidad") a manera de ariete ideológico para contrarrestar la avanzada "colonialista" hispanizante. 
Norteamérica como parte del proyecto revolucionario, e iniciará una etapa de reconciliación con sus raíces hispánicas. De ahí deriva el sentido de su trabajo de rescate al sentenciar:

Nunca como ahora se impone, a todos los que podamos, el deber de escribir nuestras memorias y dejar consignado lo que sepamos respecto de los nuestros y lo que recordemos de nuestras antiguas costumbres, porque las antiguas familias de México desaparecen bajo la ola invasora de hordas yanquis, judias, sirio-libanesas, árabes, yo no sé que más; y como es natural, las costumbres se van sin dejar recuerdo. Todo esto se ha venido no en forma lenta, como antes sucedía, sino precipitadamente a partir de la revolución de 1910, acentuándose más a causa de las renovaciones que en todos los órdenes han traído, para bien o para mal, la guerra europea, el costo y las exigencias de la vida obligando a la mujer a salir de la casa y trabajar e ilustrarse y los grandes inventos del automóvil, de la radio, aun de la luz eléctrica, que haciendo desaparecer la luz de la vela o del quinqué, e iluminando por igual los ángulos de la antigua asistencia, ha dispersado a la familia, que antes se estrechaba para oír leer o para oír los comentarios del día alrededor de aquellos focos de luz. ${ }^{13}$

Los años que siguen a la fase armada de la revolución y a la guerra que señaló el fin de la vieja Europa, significaron el inicio de un proceso creciente de intensas innovaciones tecnológicas y administrativas acordes con las nuevas formas de acumulación del capital. Si en el párrafo anterior, con toda su carga xenofóbica, la preocupación central gira en torno a los efectos desarticuladores de la idea de familia que Esquivel Obregón conoció en su infancia y juventud, el escenario natural de su memoria tendrá que ver más directamente con la historia de León, su ciudad natal. Así, añade:

Es una verdad, tan grande comoen general desconocida o poco tenida en cuenta, la que asienta don Ignacio Ramírez de que la tradición oral no pasa más allá de tres generaciones. [...] La historia de la ciudad de León, generalmente descuidada por sus hijos, proporciona un ejemplo prácti$c o$, pues apenas se sabe de ella nada que pase de dos generaciones, si no es por los pocos papeles que han podido sobrevivir a la incuria y al destructor incendio, o por vagas tradiciones, algunas de ellas tan falsas como las que aseguran que allí vivieron los hermanos Aldama, que ha acabado aun por señalar la casa que habitaron según la fantasía de alguien a quien plugo asegurar tal cosa. ${ }^{14}$

Esta "modernidad", apoyada en la capacidad tecnológica, tiende a erosionar todo recuerdo que tenga que ver con el pasado, con las tradiciones, que convierte las líneas de continuidad en la ilusión de unos puntos suspensivos. De ahí que a la historia, vista como algo que notiene que ver con la vida, se la acabe por depositar en lugares ad boc como los museos-mausoleos. En Esquivel Obregón, esta conciencia se expresa cuando señala que estos tiempos no se cuidan "de dejar algo para los que vengan detrás", olvidándose "de rendir el debido tributo a las virtudes de los desaparecidos". Así, ante los embates de esta modernidad prolongada, de la que ha sido testigo incluso antes de la revolución, sus $M e$ morias se presentan como una manifestación de conservación conmemorativa del pasado, y de resistencia a la dinámica del olvido.

\footnotetext{
${ }^{14} \mathrm{Ibid}$., t. I, p. 8.
} 
LA ESTRUCTURA DEL TEXTO Y LAS FORMAS DE LA MEMORIA

Recordar no es la reexcitación de innumerables huellas fijas, fragmentarias y sin vida. Es una reconstrucción, o construcción, imaginativa edificada con la relación entre nuestra actitud hacia toda una masa activa de reacciones o experiencias pasadas organizadas y hacia un pequeño detalle destacado que generalmente se presenta en forma de imagen o de lenguaje. Por ello, casi nunca es verdaderamente exacta, ni siquiera en los casos más rudimentarios de memorización maquinal, y no tiene la menor importancia que asi sea.

Frederic C. Bartlett, 1932

VII

En 1888 recibe el título de abogado en la Escuela Nacional de Jurisprudencia. A su profesión unirá una preocupación por la historia vista como destino, tanto familiar como nacional. ${ }^{16}$ Sobre estas coordenadas girarán sus actividades profesionales y políticas después de su "rectificación". Si se puede decir que toda existencia humana esconde un drama, en Esquivel Obregón éste tiene que ver como se ha visto, por el giro que los asuntos públicos y privados tomaron en México con la revolución y en el mundo, por la guerra europea. Entre 1905 y 1915 , el paso del tiempo, más lento y parsimonioso, se tornará más acelerado y fuera de control para quienes como Esquivel Obregón

is Citado por Rosenfield, "Nueva", 1989, p. 32.

16 "El destino de México" fue el discurso que pronunció Esquivel Obregón enla Academia Mexicana de la Historia al ser recibido en la misma el historiador jesuita José Bravo Ugarte, en 1945. Este último llegó a ocupar el lugar dejado por el historiador Carlos Pereyra "paladin de nuestra raza hispanoamericana". Esquivel Obregón, "Destino”, 1945 , p. 5. Esquivel Obregón deja sentado que el destino mexicano se llama "Hispanoamérica". han nacido en pleno siglo xIX. En el torbellino del cambio muchos sucumbirán en los campos de batalla. Otros, afectados en su pensamiento, vida y obra, buscarán asideros interiores o exilios exteriores para sobrevivir al manemagnum. Esquivel Obregón, no queriendo olvidar su origen liberal paterno, pero tampoco sin poder desprenderse de la filiación porfirista propia de su tiempo, se situará en el ojo de la tormenta, para muy pronto quedar desbordado por el desarrollo de los acontecimientos.

Cuando Esquivel Obregón "hace memoria" durante estos años, no se aleja de su actividad profesional como jurisconsulto. No "recuerda de memoria". En todo caso intenta poner orden a lo pasadopasado en un acto de conmemoración y de conmiseración ante lo que, desde su percepción, va dejando de ser.

El texto de las Memorias es una especie de miscelánea en la que se encuentra de todo: efemérides, relatos y anécdotas de sobremesa, transcripción de textos y poemas extraídos de fuentes primarias u otros autores. Muchos son testimonios tomados de la tradición oral, familiar y a veces popular. En otras partes lo escrito son los resultados obtenidos por su propia observación, sobre todo al describir calles y edificios de la ciudad de León o de la de México. Así se va tejiendo una red en la que se mezcla lo trivial, lo cómico y lo trágico, con lo solemne o supuestamente digno de contarse. Las arterias principales de este recorrido que va en lo fundamental de 1864 a 1888 , están atravesadas por la presencia de la madre, y en general por personajes ligados a la familia. Como en una sala de museo o pasajes de una enciclopedia, se desfila ante personajes de la vida política y cultural local. Las descripciones de vida cotidiana son frecuentes en el texto, vistas desde la óptica del lente de las prác- 
ticas y experiencias de una "familia decente". Horarios de comidas, clases de alimentos y de bebidas, prácticas religiosas, tipos de trajes y vestidos, son miradas hechas desde la óptica de un "anticuario". No menos interesantes son sus apuntes sobre los libros y hábitos de lectura, de lo permitido y lo prohibido, todo lo cual proporciona elementos para entender procesos de formación de "hábitos de pensamiento".

Las referencias a la educación formale informal en la ciudad de León están bien documentadas. Lo mismo una visión de la arquitectura, urbanización y demografia leonesa hasta 1888 , año de la inundación. Aparecen también descripciones de fiestas y reuniones sociales, prâcticas religiosas, relaciones raciales y de clase entre la población, relaciones ideológicopolíticas, pero sobre todo, familiares y emocionales, en las que las fibras del conflicto entre la Iglesia y el Estado son apenas perceptibles.

Se ha señalado ya que el objeto principal de las Memorias es preservar un cierto patrimonio de la familia Esquivel Obregón, lo mismo que buscar la continuidad de un cierto linaje familiar. Pero esta intención se ve acompañada casi inevitablemente de la exposición enciclopédica de hechos y señales de la vida del León de entonces. De modo que la autobiografia formará parte de la evolución comercial, industrial, cultural y profesional de la ciudad y de los habitantes encargados de dar forma al impulso "civilizador".

El marco básico temporal está ubicado entre 1864-88. Desde éste se harán incursiones hacia adelante o hacia atrás, según se vea conveniente para proporcionar un mayor cuerpo a la historia familiar, pieza fundamental de la nacionalidad; así se referirá a la llegada de los jesuitas a León en 1730.
La estructura de la obra no mantiene un orden expositivo. Con mucha frecuencia el autor se desvía del camino, tomando otras veredas, para retomarlo páginas adelante. Por eso se tiene la impresión a veces de estar ante un manuscrito realizado sobre las rodillas, en el que no existe ni se tiene la idea de un plan prefijado. Tal vez esto se deba a que su autor no pensaba publicarlas, pero también a una cierta prisa por zurcirsobre el fondo dela modernidad revolucionaria, aspectos de la memoria que por si mismos podrían aparecer como marcas de distinción en relación a la época presente.

VIII

Sólo queda por examinar la forma como esta "memoria" se fue estructurando. La pregunta clave a dilucidar es, primero, si esta forma de rescate del pasado pertenece o no a un género literario más amplio aparecido antes de la revolución, que incluso logre atravesarla y permanecer y, segundo, si esta práctica, conforme la revolución se fue adentrando en el siglo xx, previsiblemente fue perdiéndose o quedando relegada, debido a la aparición y consolidación de una nueva práctica historiográfica profesionalizante, la cual se fue apoderando de ciertos espacios vitales relacionados con este tipo de producción y difusión de la cultura del pasado.

En el caso de Esquivel Obregón una buena parte del contenido de las $\mathrm{Me}$ morias está formado por apuntes y notas de "diario" manuscritas, que su autor fue realizando a lo largo del tiempo. Así, a grosso modo se trataría de una recopilación, ni original ni privilegiada, de registros sociales e individuales, sobre el León que lo vio nacer y crecer, y la ciudad de México que supo de sus primeros pasos como estudiante de derecho. 
Gracias a la conservación de algunas de las libretas originales se puede rastrear la forma como se fue haciendo una retranscripción o simple transcripción -que añadía, suprimía o corregía el texto-, de un papel a otro, de una fecha a otra, aspectos que su autor juzgó en ese momento como dignos de conservación. Algunas veces, incluso, es posible encontrar fichas aisladas en las que se puede advertir cómo recoge alguna información relativa a León de alguna fuente oficial como la Memoria o informe de gobierno del jefe político Lorenzo Arellano, para los años de 1849 y 1850.

A la manera de los viejos copistas, por ejemplo, es posible encontrar en una de las libretas referidas a la historia y geografía de León, la copia manuscrita de su "puño y letra de un cuaderno impreso (único que se conserva) propiedad del autor...", sobre Apuntes geográficos $y$ estadísticos de la ciudad de León escritos por el profesor de geografia, doctor José García Saavedra "para el adelanto de los alumnos de la escuela de la sociedad de enseñanza popular". ${ }^{17}$

Esquivel Obregón aclara en su libreta que la copia "ha sido hecha con todo escrúpulo, conservando hasta la puntuación del original, y sólo variando lo que estaba indicado en la fe de erratas y alguno que otro error notoriamente de imprenta". Lo rubrica su firma con la fecha de marzo 9 de 1893, cuando es profesor en la Escuela de Instrucción Secundaria de León y director y principal redactor del periódico La Prensa. Durante estos años cultivará su preocupación por la historia, y sus maestros en historia de México serán los trabajos de Antonio García Cubas y de Luis Pérez Verdía, entre otros, incluidos los de su primo Luis González Obregón.

${ }^{17}$ Garcia Saavedra, Apuntes, 1872.
Estos autores parecen ser fundamentales para entender el desarrollo de un género historiográfico que tendrá buena acogida en las escuelas, por lo menos hasta los años treinta de este siglo.

Una lectura del libro de Antonio García Cubas, El libro de mis recuerdos, ${ }^{18}$ publicado en 1904, es un buen ejemplo de esta forma de "hacer memoria" o de recuperación del pasado y de sus razones. Por ejemplo, Esquivel Obregón podría haber concluido una introducción a sus Memorias con las mismas palabras con que lo hace García Cubas:

Al abrir el libro de mis recuerdos se levanta el velo de lo pasado y aparece en la escena una sociedad que, por sus costumbres, difiere esencialmente de la actual. En aquélla brillaba más el elemento moral y en ésta resalta el elemento material: fúndanse en uno ambos caracteres y la nación será grande. ${ }^{19}$

García Cubas parece ser tan importante para situar estas Memorias como parte de un "género", que los Apuntes del doctor García Saavedra-que transcribe y que más tarde quedarán integrados en sus Memorias de los años treinta-, se proponen expresamente complementar el Compendio de geografía universal escrito por García Cubas; esto debido a que considera la importancia que tiene León entonces, como segunda población de la república en número de habitantes y por ser el lugar de su nacimiento.

Pero al mismo tiempo, el estilo y ordenamiento de los materiales de esa memoria que necesita de la escritura para poder preservarse, contiene elementos

${ }^{18}$ García Cubas, Libro, 1950.

${ }^{19} \mathrm{El}$ subtítulo del libro ya de por sí es bastante sugerente: Narraciones históricas, anecdóticas y de costumbres mexicanas anteriores al actualestado de cosas. 
divagatorios que tal vez tengan que ver más con el funcionamiento real caótico e inabarcable de la memoria, cuyo único asidero firme a manera de brújula que discrimina lo que es digno de registrar de lo que no, estará dado por el presente del memorialista, apoyado en la escritura. Aunque en realidad se trate de un proceso de "reclasificación" permanente, propio al parecer del funcionamiento de la memoria. ${ }^{20}$ Sólo en este sentido es que se podría hablar de una forma discontinua enmarcada por una gran línea de continuidad en la forma de recordar el pasado. "Pasando por encima de los hechos de la revolución", sin embargo, ésta logra constituirse como gran telón de fondo de la forma de recordar más allá de la década de los años treinta.

A sus apuntes y notas sobre el pasado de la ciudad de León, Esquivel Obregón añadirá ciertos guiños provocados por la distancia generada en esta época entre el "presente revolucionario" y el "pasado porfirista". Y para ello, pese a ser de 1904, no puede uno dejar de recurrir a la elo-

\footnotetext{
${ }^{20}$ De acuerdo con recientes investigaciones que recuperan la contribución de Freud a la relación entre memoria y psicología de la vida cotidiana en el sentido de que "la memoria está presente no una sino varias veces"; y la constatación de que los neurofisiólogos aún no pueden precisar "dónde y cómo se almacenan los recuerdos"; se ha llegado a mostrar que la memoria "no es una repetición exacta de la imagen de unos sucesos en nuestro cerebro, sino una neclasificación". Es decir que las "personas nunca son exactamente lo que eran momentos antes y los objetos nunca se ven exactamente de la misma manera". De que nuestra capacidad de recordar no se debe al recuerdo específico almacenado en algún lugar de nuestro cerebro, sino que se trata "de la capacidad de organizar el mundo que nos rodea en categorias, unas generales y otras específicas", siempre en relación a contextos determinados. De esta manera se tiene que son "las necesidades y los deseos individuales, los que determinan las formas de clasificar" a las personas, los lugares y los sucesos que "llenan nuestra vida
}

cuencia de García Cubas para intentar comprender el sentido del rescate histórico de Esquivel Obregón:

En los siguientes artículos verás, carísimo lector, cuadros de costumbres nacionales que precedieron al actual orden social, y podrás observar mediante la justa comparación con los que al presente se desarrollan, lo que la sociedad ha perdido y lo que ha ganado: perdido, casi en su totalidad, su genuina y nacional fisonomía, trocada por la de caracteres extraños de servil imitación; ha ganado el don inestimable de la paz, debida a la discreta y prudente administración del general Díaz, paz bendita de que recogerá óptimos frutos la sociedad, si sabe aprovecharse de ella.

O también estas letras de García Cubas podrian haber sido suscritas por Esquivel Obregón en sus Memorias:

Lo que voy a contarte, querido lector, no se refiere a los tiempos que corren, razón por la cual, buen cuidado he tenido de estampar en el título de este artículo un adverbio de tiempo y pasado en su más

cotidiana". Además, las categorías que usamos parecendepender de "correlaciones cruzadas, es decir, del contexto". Todos estos son elementos de la Teoría de Edelman que demuestra que "el funcionamiento cerebral, como la estructura, depende también del contexto y la historia, y no de funciones localizadas y recuerdos fijos". Ésta depende del movimiento (conexiones entre los grupos neuronales de diferentes mapas reforzados temporalmente) y de la sensación. Se recoge información en diferentes contextos. Esto quiere decir, que a partir de la experiencia, "diferentes mapas" interactúan de diferente manera a como lo hicieron en un primer encuentro con la información y "ello conduce a la reclasificación". "No nos limitaremos a almacenar imágenes o datos, sino que nos enriqueceremos con la capacidad de clasificar de formas relacionadas." Rosenfield, "Nueva", 1989, pp. 25-32. El autor es matemático, médico y filosofo y enseña historia de las ideas en Nueva York. Desde hace años investiga la "invención de la menıria". 
extensa acepción, pues has dé saber que huyo siempre de las alusiones, y si alguna similitud se encuentra entre los ediles de antaño y los de hogaño, la culpa no es mía sino del que trate de avenir a unos y otros el mismo saco; y así protesto, una y mil veces, que mi relación pertenece a la historia antigua y no a la moderna. ${ }^{23}$

Y creo que, visto así, las Memorias nos proporcionan no una enseñanza para el porvenir, sino la conciencia de un hombre público acerca de cuestiones que tienen que ver sobre todo con el ámbito de lo privado, de lo íntimo. Es ahí donde Esquivel Obregón, acompañado de la lucidez que proporciona una cierta nostalgia, dificil saber si exclusiva de espíritus conservadores, nos acerca a la clave para entender el paso de México a la modernidad, centrado como decía, en las cosas pequeñas de la vida cotidiana, pues, tal vez sólo ahí, es posible detectar al pequeño-gran-hombre, si es que lo hay. Y sobre todo, que sea en ese ámbito en el que con más facilidad el historiador puede detectar, a través del desciframiento del lenguaje, los cambios interiores (de gestos y actitudes que logran afectar las acciones y las formas de comportamiento de los individuos) de una sociedad.

${ }^{21}$ Garcia Cubas, Libro, 1950, pp. 185-186.

\section{BiBLIOGRAFÍA}

-Brown, Peter, El mundo de la antigüedad tardia, Editorial Taurus, Madrid, 1989.

-Esquivel Obregón, Toribio, Mi labor en servicio de México, Editorial Botas, México, 1934. "El destinode México", Sobretiro de la Academia Mexicana de Historia, Academia Mexicana de la Historia, México 1945. Memorias, 2 vols. (original mecanografiado inédito).

-García Cubas, Antonio, El libro de mis recuerdos, Editorial Patria, México, 1950.

-García Saavedra, José, Apuntes geogrâfi$\cos y$ estadísticos de la ciudad de León, Imprenta de J. M. Monzón, México, 1872.

-Gay, Peter, Freud, una vida de nuestro tiempo, Ediciones Paidós, Buenos Aires, 1989.

-Rosenfield, Israel, "Una nueva aproximación a la memoria y la percepción", El Paseante, núm. 14, Ediciones Siruela, Madrid, 1989.

-Santos, Gonzalo N., Memorias, Editorial Grijalbo, México, 1986.

-Vázquez Gómez, Francisco, Memorias politicas, 1909-1913, UIA/Ediciones El Caballito, México, 1980.

-Yourcenar, Marguerite, El laberinto del mundo, t. I., Recordatorios, Ediciones Alfaguara, Madrid, 1984. 

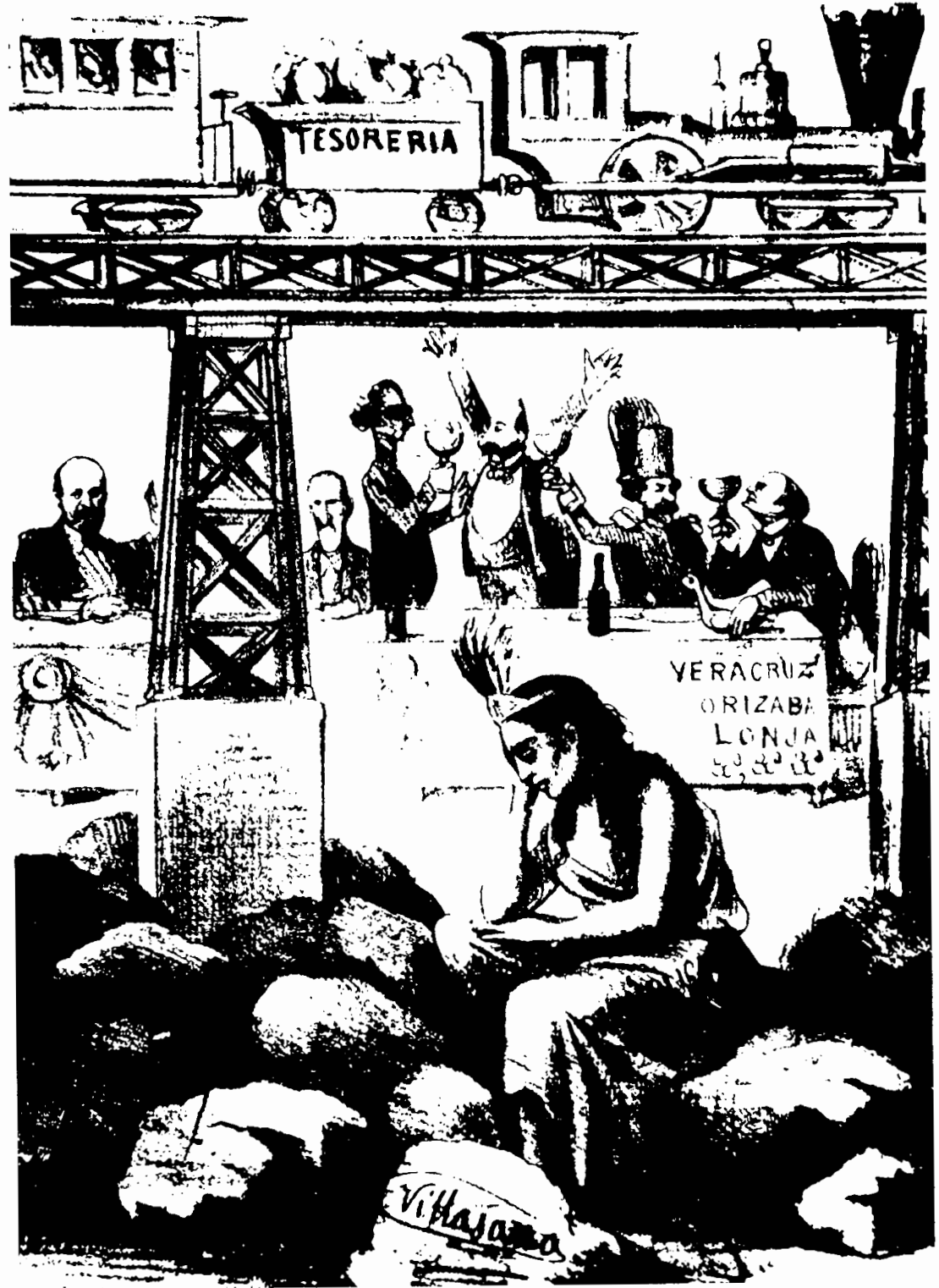